\title{
Security Complex Indonesia-Australia dan Pengaruhnya terhadap Dinamika Hubungan Kedua Negara
}

\author{
Siti Muti'ah Setyawati ${ }^{1}$ \\ Dafri Agussalim²
}

\begin{abstract}
This study aims to define security complex or the pattern of amity and enmity in the relations between Indonesia and Australia. Generally speaking, it is found that amity (cooperation) between the two is far more dominant than their enmity (hostility). The main method used to analyze whether there is a causal relationship between the independent variables and the dependent variable is the method of interpretive analytics with inductive logic thinking.

The lesson are; First, we can not act based on the expectation that the other country will be good behaviour and beneficial to us. Second, we should focus on our diplomacy to prevent Australia for not doing any harmful actions to Indonesia. Third, we must understand and more critical to Australia as a state and nation in all its aspects, in particular the dynamics of its domestic politics.
\end{abstract}

\section{Keywords:}

security complex; aminty; enmity; Indonesia; Australia.

\begin{abstract}
Abstrak
Penelitian ini bertujuan untuk menemukan karakter security complex atau the pattern of amity and enmity antara Indonesia dan Australia. Secara garis besar aspek amity (kerjasama) antara kedua negara jauh lebih dominan dari pada aspek enmity-nya (permusuhan). Metode utama yang digunakan untuk menganalisis ada tidaknya hubungan kausalitas antara independent variable dan dependent variable yaitu metode interpretive analytic dengan logika berpikir inductive.

Pelajaran yang dapat diambil yaitu; pertama, kita tidak bisa bertindak berdasarkan harapan bahwa pihak lain akan berbuat baik pada kita. Kedua,seharusnya sejak awal kita memfokuskan diplomasi kita untuk mencegah agar Australia tidak melakukan tindakan yang merugikan Indonesia. Ketiga, kita harus memahami bangsa dan negara tersebut di segala aspeknya, khususnya dinamika politik domestiknya secara lebih dalam dan lebih kritis lagi.
\end{abstract}

\section{Kata Kunci:}

security complex; amity; enmity; Indonesia; Australia.

\footnotetext{
1 Dosen Departemen Hubungan Internasional, FISIPOL UGM Email: sitimutiah.setiawati@gmail.com

2 Dosen Departemen Hubungan Internasional, FISIPOL UGM Email: dafri_agus@yahoo.com
} 


\section{Latar Belakang}

Selama ini hubungan Indonesia dan Australia sering mengalami pasang surut secara dinamis dari waktu ke waktu. Pada suatu periode tertentu hubungan kedua negara ini terlihat sangat bersahabat, kooperatif, dan saling mendukung. Namun, pada periode lainnya hubungan tersebut berubah menjadi penuh ketegangan, saling curiga, dan kurang bersahabat. Tidak jarang karakter hubungan kedua negara ini berubah sangat cepat dan dalam interval waktu yang sangat pendek.

Ketika Indonesia menerapkan politik konfrontasi terhadap Barat, seperti saat Indonesia menentang Federasi Malaysia dengan Ingris tahun 1963, hubungan Indonesia dan Australia mulai mengalami ketegangan. Ketegangan meningkat ketika Indonesia memasukkan Timor Timur menjadi provinsi ke-27 tahun 1976. Semenjak itu hingga kini, hubungan Indonesia-Australia dinamikanya sangat fluktuatif. Kedua negara kadang sangat akrab dan bersahabat, seperti di era kepemimpinan Presiden Suharto dan Perdana Menteri Paul Keating tahun 1992-1995. Namun, sering pula cepat menegang seperti masa Perdana Menteri John Howard dan Presiden B.J. Habibie, atau di era Presiden Susilo Bambang Yudhoyono dan Perdana Menteri Tonny Abbot tahun 2013-2014 (Mar'iyah, 2007).

Terdapat dua pertanyaan utama yang hendak dijawab dalam penelitian ini. Pertama, bagaimana security complex (pattern of amity and enmity) antara Indonesia dan Australia berlangsung selama ini? Kedua, apa hubungan karakter security complex yang demikian dengan dinamika hubungan kedua negara selama ini? Argumen utama yang ingin dikembangkan dalam penelitian ini adalah karakter security complex atau the pattern of amity and enmity antara kedua negara lebih diwarnai dan didominasi oleh aspek enmity (permusuhan) ketimbang aspek amity (kerja sama). The pattern of amity and enmity antara kedua negara relatif bersifat persisten, tidak terlalu banyak terpengaruh oleh perubahan lingkungan politik internal dan eksternal masing-masing. Perbenturan aspek amity dan enmity ini menjadi faktor penting yang menyebabkan perbedaaan sikap dan perilaku kebijakan luar negeri suatu negara terhadap negara lainnya, yang pada akhirnya memengaruhi dinamika hubungan keduanya dari waktu ke waktu.

\section{Metode Penelitian}

Penelitian ini dilakukan dengan metode kualitatif, artinya penelitian lebih banyak menggunakan data kualitatif seperti nilai (norm), sikap, ideologi atau pemikiran orang yang diproses dengan menghubungkan fenomena yang satu dengan lainnya. Secara khusus, untuk memahami fenomena hubungan IndonesiaAustralia, analisis data menggunakan metode interpretif. Seperti disampaikan Reed (Issac, 2011), bahwa "interpretasi" berfokus pada penelitian yang mengungkapkan pemaknaan oleh praktisi, yang dapat digunakan untuk menganalisis permasalahan yang menjadi fokus penelitian. Tujuannya untuk memahami permasalahan manusia dengan mengartikan yang diinterpretasikan oleh para praktisi. Cara ini juga dapat menginterpretasikan suatu fenomena dari kejadian yang tersembunyi di belakang fenomena tersebut (Guba dan Lincoln, 1994).

Dalam ilmu Hubungan Internasional, masih terdapat perdebatan mengenai subject matter yang perlu dianalisis, metodologi yang layak untuk diterapkan ketika seorang peneliti atau akademisi melakukan studi, serta struktur epistemologi dari teori-teori yang ada (Burchill dan Linkater, 1989: 3). Perdebatan mengenai metodologi sudah terjadi sejak tahun 1960-an, yaitu pada tahap kedua dari apa yang dikenal sebagai The Great Debates dalam disiplin ini. Perdebatan terjadi antara kubu "behavioralis" (scientists), yang percaya bahwa hubungan internasional paling tepat dipelajari dengan menggunakan metode seperti yang dilakukan dalam ilmu alam, melawan kubu 
"tradisionalis" yang berargumen bahwa studi ilmu sosial, termasuk hubungan internasional, tidak harus meniru studi empirik seperti yang dilakukan dalam ilmu alam (Burchill dan Linkater, 1989).

Penelitian ini juga menggunakan pendekatan behavioralis yang melahirkan aliran positivisme, ilmu pengetahuan (knowledge) yang hanya mungkin dihasilkan melalui pengumpulan data-data yang dapat diamati dan diukur (observable and measureable data). Melalui pengumpulan data seperti ini, dapat diidentifikasi pola-pola regularitas yang akhirnya bisa digunakan untuk memformulasikan hukum-hukum regularitas tersebut. Pendekatan ini diharapkan lebih memudahkan dalam menganalisis fenomena "security complex" antara Indonesia dengan Australia, selain metode interpretasi.

Menurut Milja Kurki dan Colin Wight, terdapat perdebatan yang ditandai oleh explanatory theory dan understanding theory, atau antara pendekatan scientific dan pendekatan interpretive atau hermeneutic approach, antara positivisme dan post-positivisme, serta antara rasionalisme dan reflektivisme (2012: 3). Sementara para teoretikus explanatory mengedepankan prinsip dan metode ilmiah seperti yang dipakai pada ilmu alam, teoretikus understanding lebih fokus pada analisis makna internal, argumen, dan kepercayaan yang diyakini aktor. Bagi pendukung understanding theory, makna sosial, bahasa, dan kepercayaan merupakan aspek ontologis terpenting dari eksistensi sosial. Sebaliknya, pendukung explanatory theory mengatakan bahwa kepercayaan dan ide tidak dapat dibuktikan secara empiris dan oleh karena itu tidak dapat dijadikan motode untuk memperoleh ilmu pengetahuan (Kurki dan Wight, 2012: 20).

Penelitian ini menggunakan pendekatan konstruktivisme--yang lebih relevan dengan understanding theory. Oleh karena itu digunakan metode interpretif mencakup kualitatif, diskursif dan historis, yang berfokus pada interpretasi dari unobservable dan immeasurable data (Milja dan Kurk, 2012:20).

Penelitian ini bersifat descriptive-explanative yang digunakan untuk menggambarkan "what is the case," sedangkan eksplanasi berfokus pada "why something in the case." (Punch, 2005: 15). Deskripsi dan eksplanasi dilakukan dengan metode interpretif dan logika berpikir induktif. Data yang tersedia diinterpretasikan dengan cara memberi makna dan arti, diterjemahkan sehingga dapat dimengerti. Interpretasi dilakukan untuk menemukan bagaimana agen atau aktor yang sedang dikaji melihat dunia, bagaimana mereka mendefinisikan atau mengonstruksi situasi, dan apa artinya semua itu bagi mereka (Newman, 2003: 148).

\section{Memahami Konsep Security Complex}

Barry Buzan (1991) berpendapat bahwa keamanan pada dasarnya adalah suatu fenomena relasional (relational phenomenon). Oleh karena itu, keamanan suatu negara atau beberapa negara dalam suatu kawasan tidak dapat dipahami tanpa lebih dulu memahami pola hubungan saling ketergantungan keamanan, di antara negara-negara kawasan tersebut. Dalam memahami keamanan regional ini, Buzan menawarkan konsep security complex. Ia mendefinisikan security complex sebagai "a group of states whose primary security concern link together sufficiently closely that their national security cannot realistically be considered apart from one another" (Buzan, 1991 : 8). Konsep ini mencakup aspek persaingan maupun kerja sama di antara negara-negara terkait.

Karakter security complex yang mencakup "interdependence of rivalry as well as that of shared interest" oleh Buzan diistilahkan dengan "pattern of amity and enmity among states." Amity adalah hubungan antarnegara yang terjalin mulai dari rasa persahabatan sampai ekspektasi akan mendapatkan dukungan atau perlindungan satu sama lain. Sementara itu, Buzan menggambarkan enmity sebagai suatu hubungan antarnegara yang terjalin 
atas dasar kecurigaan dan rasa takut satu sama lain. Pattern of amity/enmity ini dapat muncul dan berkembang akibat berbagai isu yang tidak dapat dipahami hanya dengan melihat distribution of power yang ada di antara negara-negara terkait. Pattern of amity/ enmity dapat datang dari berbagai hal yang bersifat spesifik seperti sengketa perbatasan, kepentingan yang berkaitan dengan etnis tertentu, pengelompokan ideologi dan warisan sejarah lama baik yang bersifat negatif maupun yang bersifat positif, serta distribusi kekuasaan di antara negara-negara atau di kawasan tertentu (Buzan, 1991).

\section{Aspek Amity dan Enmity dalam Hubungan Indonesia-Australia}

Dilihat dari aspek sejarah, hubungan Indonesia-Australia memiliki sisi amity dan enmity yang cukup kuat, dengan aspek enmity yang lebih menonjol. Pada sisi Indonesia, aspek amity terhadap Australia mulai tumbuh dan berkembang sejak Indonesia masih berjuang untuk kemerdekaan. Hubungan yang sangat akrab ditunjukkan oleh dukungan Australia kepada Indonesia dalam menghadapi Belanda. Pemerintah Australia, khususnya Partai Buruh, tidak mengizinkan kapalkapal Belanda berlabuh di Australia. Richard Kirby juga bersedia menjadi mediator dalam konflik Indonesia-Belanda setelah Australia bergabung dalam Komisi Tiga Negara atau United Nations Special Commission on Indonesia (UNCI). Australia pun sangat berperan dalam membangun opini publik internasional, untuk ikut mendukung perjuangan Indonesia.

Dalam Strange Neighbours: IndonesiaAustralia Relationship (1991), Bail Desmond menjelaskan bahwa Australia dan Indonesia mempunyai keistimewaan. Dua negara tetangga biasanya mempunyai kemiripan, paling tidak dalam etnis, budaya, dan agama yang kemudian berdampak pada kemiripan lain misalnya kepentingan nasional, politik luar negeri, dan masalah keamanan. Istimewanya,
Indonesia dan Australia sangat berbeda dalam hal etnis atau ras, budaya, dan agama. Mayoritas penduduk Australia adalah ras Kaukasus yang berasal dari Eropa, khususnya Belanda, yang datang kurang lebih di awal abad ke-17 dan Inggris yang datang di bawah Kapten James Cook tahun 1770, yang kemudian mengklaim pantai timur Australia untuk Inggris dan dilanjutkan pantai barat. Pada perkembangannya Australia memang dihuni oleh berbagai etnis dari seluruh dunia, tetapi mayoritas tetap berkulit putih. Sedangkan penduduk asli Indonesia termasuk ras Mongoloid.

Biro Statistik Australia mencatat bahwa tahun 2013 penduduk negara itu berjumlah 23 juta jiwa dengan pertumbuhan 1,7 persen per tahun (Kompas, 26 Oktober 2015). Sementara penduduk Indonesia pada tahun 2011 berjumlah 260 juta jiwa. Hal ini dipengaruhi oleh kondisi ekonomi yang berbeda antara kedua negara. Australia merupakan negara ekonomi maju dengan Produk Domestik Bruto (PDB) sebesar $\$ 2,7$ triliun US pada 2014 (Australian Bureau of Statistic, December 2015 ), sedangkan PDB Indonesia di tahun yang sama adalah $\$ 888,54$ miliar (www.tradingeconomics.com/indonesia/ gdp). Berdasarkan latar belakang tersebut, dapat dipahami bahwa yang dimaksud ancaman dan security complex bagi kedua negara berbeda.

Jamie Mackie, dalam Australia and Indonesia: Current Problems, Future Prospects (2007) menggambarkan hubungan IndonesiaAustralia yang mengalami pasang surut karena perbedaan menonjol dalam hal kondisi ekonomi, jumlah penduduk, etnis, budaya, dan agama. Hal-hal yang dikhawatirkan oleh Australia ialah serangan militer dari Indonesia, infiltrasi teroris muslim, dan masuknya para pengungsi dari Papua dan wilayah konflik lain di Indonesia karena kedekatan geografis. Kekhawatiran semakin menguat ketika Natasha dan Dave (2015) mengambarkan prinsip politik luar negeri yang bebas dan aktif telah 
menghalangi Indonesia untuk membangun aliansi militer secara formal.

Indonesia tidak mungkin diharapkan bisa bekerja sama membangun aliansi militer dengan Australia. Oleh karena itu, Australia berkepentingan untuk menjaga keberlangsungan Negara Kesatuan Republik Indonesia, membantu Indonesia untuk mempertahankan keistimewaannya sebagai negara yang mayoritas beragama Islam moderat dan toleran, mempertahankan kebhinekaan Indonesia dengan ideologi Pancasilanya, memajukan pendekatan people to people, dan memperkenalkan demokrasi sebagai cara pengelolaan pemerintahan (Wawancara dengan Prof.Dr.Richard Tanter, Victoria University, Melbourne 23 Desember 2015).

Selama ini, Australia telah menerapkan politik luar negeri yang menghindari konflik militer dengan Indonesia, khususnya sejak pasukan Australia diterjunkan ke Timor Leste tahun 1998. Australia juga telah merasa membantu mewujudkan kesejahteran dan stabilitas keamanan kawasan. Meskipun demikian, kekhawatiran Australia akan munculnya "Islam ekstremis" seperti Al Qaeda dan Jamaah Islamiyah sempat mengganggu hubungan baik dengan Indonesia. Ditambah lagi peristiwa Bom Bali 2002 dengan korban mayoritas orang Australia dan bom di Kedutaan Australia tahun 2004. Demi mengatasi kendala ini pemerintah Australia telah berupaya meningkatkan hubungan dengan pertukaran budaya dan pendidikan serta mendirikan Consultative Council untuk mencegah konflik di antara kedua negara.

Menariknya, aspek enmity Australia yang kuat terhadap Indonesia tidak berarti menutup sama sekali aspek amity keduanya. Pada dasarnya, sekalipun kedua negara mempunyai banyak kepentingan dan cara pandang yang berbeda, mereka juga memiliki sejumlah titik temu kepentingan. Salah satu faktor penyumbang menguatnya aspek amity adalah kedekatan geografis. Kedua negara berbatasan langsung dengan dipisahkan oleh Samudera Hindia dan Laut Timor. Namun kedekatan geografis ini juga berpotensi menimbulkan gesekan-gesekan yang bisa mengarah kepada konflik.

Faktor lain yang telah memperkuat amity adalah kepentingan ekonomi dan perdagangan. Australia membutuhkan Indonesia sebagai "pasar" terutamajasa, produk-produk pertanian dan peternakan, juga negara tujuan investasi bidang pertambangan, pendidikan, dan lainlain. Indonesia membutuhkan Australia sebagai sumber modal dan bantuan ekonomi. Pada bidang pertahanan dan keamanan, Australia membutuhkan Indonesia sebagai "negara penyangga" dari kemungkinan munculnya gangguan keamanan dari utara. Misalnya, membendung aliran kejahatan transnasional seperti penyelundupan narkotika, perdagangan manusia, imigran ilegal, dan lain sebagainya. Pun sebaliknya, Indonesia memerlukan Australia untuk bantuan teknis dan keuangan dalam operasi-operasi menjaga keamanan dan stabilitas kawasan, dari tindak kejahatan transnasional.

Kedua negara juga saling membutuhkan di bidang sosial, budaya dan pendidikan. Indonesia membutuhkan bantuan Australia untuk memberikan beasiswa bagi pelajarnya untuk belajar di sana. Sementara Australia membutuhkan Indonesia sebagai pasar bagi industri pendidikannya, yang dapat pula menjadi sarana diplomasi guna mendekatkan hubungan dengan Indonesia.

Hubungan yang baik setelah perang kemerdekaan Indonesia tidak berlangsung lama, pasang surut terjadi ketika Presiden Soekarno begitu agresif dengan gerakan "anti-Barat"-nya mendirikan Gerakan Non Blok, yang dilanjutkan dengan merapat ke Uni Soviet dan akhirnya membentuk "politik poros-porosan"seperti Poros Jakarta-Peking, Jakarta-Pyongyang, dan Jakarta-Moskow. Ketika Australia membantu Malaysia saat Indonesia melakukan politik konfrontasi 
terhadap Negeri Jiran tersebut tahun 19631966, hubungan Indonesia-Australia terus memburuk meski tidak sampai putus (Evan dan Grant, 1993: 186).

Hubungan yang sempat merenggang merapat kembali ketika Soeharto naik ke puncak kekuasaan tahun 1967. Didorong oleh kebutuhan akan dukungan politik dan ekonomi dari Barat, Soeharto menerapkan politik bersahabat dengan Barat, yang juga berarti lebih bersahabat dengan Australia. Hubungan erat kembali terganggu ketika Indonesia mengintegrasikan Timor-Timur ke dalam wilayahnya tahun 1975 . Kebijakan tersebut ditentang keras oleh Australia. Namun, tahun 1979 Australia secara de jure mengakui bahwa Timor-Timur merupakan bagian dari wilayah NKRI, yang di kemudian hari diperkuat lagi dengan ditandatanganinya perjanjian Celah Timor tahun 1989.

Antara tahun 1979-1985 hubungan Indonesia-Australia berjalan relatif normal, hanya sesekali diwarnai kontroversi. Tetapi, tahun 1986 kembali memanas saat wartawan The Sydney Morning Herald, David Jenkins, menulis suatu artikel panjang tentang korupsi yang dilakukan oleh Soeharto dan keluarganya (Evan dan Grant, 1993: 187). Pemerintah bereaksi keras, mengatakan bahwa artikel tersebut menghina kepala negara Indonesia, yang berarti pula menghina bangsa Indonesia. Indonesia mengancam akan membekukan hubungan dengan Australia jika tidak ada upaya untuk mencabut artikel dan meminta maaf pada bangsa Indonesia. Kebekuan hubungan diplomatik kedua negara ini mencair dan kembali normal tidak lama sesudahnya. Bahkan, dalam periode 1986-1990 hubungan Indonesia-Australia relatif berjalan baik.

Hubungan Indonesia-Australia kembali memanas akibat meletusnya peristiwa Santa Cruz di Timor-Timur tahun 1991, yang menelan beberapa korban jiwa. Reaksi Australia, khususnya sebagian masyarakatnya, sangat keras. Di kalangan masyarakat Australia, fokus isu bergeser dari masalah politik ke isu hak asasi manusia (HAM). Indonesia diangap telah melanggar HAM. Oleh karenanya, masyarakat Australia menuntut pemerintahnya agar merespon isu tersebut dengan lebih keras. Kurang dari satu tahun dari insiden tersebut hubungan kedua negara kembali normal. Hal tersebut menunjukkan bahwa sebuah insiden sempat membuat hubungan kedua negara menjadi tegang, tetapi hubungan diplomatik keduanya tidak pernah terputus.

Sejak tahun 1992 sampai 1994, bersamaan dengan naiknya Paul Keating dari Partai Buruh sebagai Perdana Menteri Australia, dapat dikatakan hubungan Indonesia-Australia berada di puncak masa bulan madunya. Politik luar negeri Australia sangat dekat dan akomodatif terhadap negara-negara tetangganya di Asia, terutama Indonesia. Hal ini berdampak positif bagi berkembangnya hubungan Indonesia-Australia ke arah yang konstruktif dan saling menguntungkan.

Terdapat banyak program kerja sama yang dibuat oleh Indonesia dan Australia, di masa pemerintahan Keating. Salah satu yang penting adalah ditandatanganinya Perjanjian Kerja Sama Keamanan atau Agreement on Maintaining Security (AMS) tahun 1994, walaupun perjanjian ini kemudian dibatalkan pasca jajak pendapat di Timor-Timur. Hubungan politik, keamanan, sosial, dan ekonomi baik yang bersifat bilateral maupun multilateral seperti di APEC, ASEAN, dan lain-lain berjalan baik. Akibat begitu dekat dan akomodatifnya kebijakan Keating terhadap Indonesia waktu itu, media Australia sering menjulukinya sebagai "diplomat" Indonesia dibanding Perdana Menteri Australia. Paul Keating mungkin satu-satunya pemimpin negara asing yang mengunjungi Indonesia hingga empat kali dalam setahun.

Hubungan kedua negara kembali mengalami ganjalan dengan naiknya John Howard dari Partai Liberal menggantikan Keating. Retorika dan kebijakan luar negeri Howard dinilai terlalu condong ke Amerika 
dan anti-Asia, yang menimbulkan kegusaran banyak pemimpin Asia, terutama Indonesia. Puncak kegusaran akhirnya meletus ketika Australia mengajukan diri untuk menjadi negara yang mengambil peran utama untuk menjalankan misi Perserikatan Bangsa-Bangsa menjaga perdamaian di Timor-Timur, yang telah berganti nama menjadi Timor Leste setelah referendum. "Jakarta" merasa dikhianati oleh "Canberra" mengingat Australia awalnya mendorong atau "merestui" pengintegrasian Timor-Timur.

Dampak insiden ini cukup hebat, sampai menyebabkanmaraknyagerakan dan demonstrasi bukan saja anti pemerintah Australia, tetapi juga anti orang Australia, di mayoritas kota besar Indonesia. Namun, menegangnya hubungan tersebut tidak pula berakhir dengan pemutusan hubungan diplomatik. Hubungan kedua negara kembali pulih dalam waktu yang tidak terlalu lama. Pada awal pemerintahan Presiden Susilo Bambang Yudhoyuno, hubungan kedua negara kembali menunjukkan perkembangan pesat, terlihat dari meningkatnya hubungan sosial, politik, ekonomi, dan perdagangan kedua Negara.

\section{Karakter Hubungan yang Tampak}

Selain karakter dasar yang penuh dengan sensitivitas dan ganjalan serta potensi positif, dinamika hubungan kedua negara sebagaimana diuraikan di atas juga menunjukkan beberapa karakter penting yang selalu melekat dan mewarnai hubungan Indonesia-Australia. Pertama, yang menjadi masalah dalam hubungan kedua negara ini umumnya berpangkal dari masalah yang berkembang di Indonesia. Hubungan tidak pernah terganggu misalnya, karena Indonesia menggugat, mengkritik, atau menyerang secara fisik Australia terlebih dahulu. Masalah selalu muncul sebagai reaksi Indonesia terhadap respon Australia atas isu yang berkembang di Indonesia sendiri, misalnya kasus integrasi dan kemudian lepasnya Timor-Timur, kasus David
Jenkins, insiden Santa Cruz, dan terakhir kasus Visa 42 (Mar'iyah, 2007).

Kedua, masalah dalam hubungan lebih sering berasal dari masyarakat, baik individual atau kelompok, bukan dari dan oleh kedua pemerintah. Dengan kata lain, yang disebut oleh Buzan sebagai security complexes (pattern of amity dan enmity among states) di tingkat pemerintah atau negara relatif rendah. Masalah yang sesunguhnya, terutama di pihak Indonesia, cenderung berasal dari masyarakat yang ditarik ke atas menjadi masalah negara. ${ }^{3}$ Kedua pihak cenderung melakukan semacam "nasionalisasi" suatu isu, misalnya dengan melakukan sekuritisasi atau bahkan politisasi terhadap isu-isu tersebut demi kepentingan yang beragam (Buzan, 1991).

Ketiga, sebagian besar masalah sebenarnya terjadi karena kegagalan diplomasi atau komunikasi politik. Hal ini dibuktikan dengan adanya fakta bahwa meski hubungan IndonesiaAustralia sangat sering memanas, tetapi belum pernah berkonflik atau perang secara langsung. Keempat, khususnya dikaitkan dengan penjelasan poin ketiga, kedua negara sesungguhnya saling menyadari bahwa potensi yang dikandung dalam hubungan mereka sangat besar bagi kepentingan nasional masing-masing. Kedua negara ini menyadari bahwa sesungguhnya mereka saling membutuhkan satu sama lain.

\section{Dinamikan Hubungan Negara Tetangga Indonesia-Australia}

Sangat menarik untuk menganalisis alasan Indonesia dan Australia yang secara geografis sangat berdekatan dan mempunyai kepentingan timbal-balik yang tinggi, mempunyai hubungan yang begitu sensitif dan

\footnotetext{
Contohnya adalah kasus David Jenkins dan pemuatan karikatur Presiden Indonesia dan Perdana Menteri Australia oleh media di kedua negara baru-baru ini. Sedangkan dalam karikatur, di Indonesa dibuat karikatur Tony Abbot yang menyadap Presiden SBY, dimuat di Koran Rakyat Medeka pada 23 November 2013 sebagai balasan atas dimuatnya Karikatur Presiden SBY oleh The Canberra Time pada 20 November 2013.
} 
sering pasang surut. Dalam teori geopolitik, negara yang bertetangga umumnya mempunyai banyak kemiripan, termasuk etnisitas, budaya, agama, dan pengalaman sejarah. Inilah yang kemudian menjadi faktor integrasi dua negara ataupun integrasi kawasan; semakin banyak kemiripan, semakin mudah negara-negara bersatu. Namun, tampaknya hal ini tidak berlaku bagi hubungan Indonesia-Australia. Kedua negara memiliki perbedaan signifikan, di hampir semua bidang, seperti pernah dikatakan oleh Paul Keating:

"No two neighbours anywhere in the world are as comprehensively unalike as Australia and Indonesia. We differ in language, culture, religion, history, ethnicity, population size and in political, legal, and social systems. Usually neighbours share at least some characteristics brought about by proximity over time, but the Indonesian archipelago and the continental land mass of Australia might well have been half a world apart". (Evan dan Grant, 1993: 184)

Perbedaan-perbedaan yang kontras tersebut telah menyulitkan keduanya untuk saling berkomunikasi dan memahami kebutuhan dan kepentingan masing-masing, di berbagai bidang. Meski begitu, keduanya menyadari bahwa sebenarnya saling membutuhkan. Masyarakat dan pemerintah Australia selalu berasumsi dan berharap bahwa seharusnya bangsa dan pemerintah Indonesia dapat memahami setiap apa yang mereka lakukan beserta nilai-nilai yang mendasarinya. Cara pendekatan seperti itu tercermin dari pernyataan yang dikeluarkan oleh Menteri Luar Negeri Australia Alexander Downer: "Our economic security...our border security... and our ability to help shape a more secure world... all rely on Australia exercising a strong, independent, responsive and pragmatic foreign policy." ${ }^{4}$

4 Pidato Alexander Downer pada peluncuran publikasi
Penolakan Australia untuk mencabut artikel tentang korupsi Soeharto, menghukum David Jenkins selaku penulis, dan meminta maaf terhadap bangsa Indonesia dengan berargumen bahwa pemerintah tidak dapat ikut campur dalam kehidupan pers yang bebas di negara itu, membuktikan cara pandang dan pendekatan seperti di atas. Demikian juga penolakan Australia terhadap tuntutan Indonesia untuk membatalkan pemberian visa kepada 42 Warga Negara Indonesia (WNI) asal Papua, dengan mengatakan bahwa pemerintah Australia tidak berwenang untuk campur tangan dalam masalah hukum di negara lain. Dua kasus penolakan tersebut secara implisit mengandung himbauan agar Indonesia mengerti dan memahami norma dan sistem hukum dan politik yang berlaku di Australia.

Australia juga terkadang menginterpretasikan politik luar negeri Indonesia yang bebas aktif, kurang bersahabat dengan Barat. Meskipun di awal era Presiden Soeharto berkuasa kecurigaan itu tidak terbukti, tetapi pada masa Soekarno dengan PNI dan Jokowi dengan PDIP kekhawatiran tersebut bisa dipahami. Orientasi politik luar negeri Indonesia di bawah PNI yang anti Barat diwarisi oleh PDIP, yang dianggap kelanjutan PNI. Sebaliknya, pemerintah dan bangsa Indonesia juga selalu berharap dan berasumsi bahwa masyarakat dan pemerintah Australia seharusnya dapat memahami perasaan dan nilai-nilai yang berlaku dalam masyarakat Indonesia.

Sejalan dengan itu, Indonesia berasumsi dan berharap pula agar Australia dapat memasukkan nilai, norma, serta sistem-sistem sosial, politik dan hukum yang berlaku di Indonesia sebagai bahan pertimbangan dalam setiap pembuatan kebijakan. Bertolak dari kedua kasus di atas, terlihat jelas bahwa baik pemerintah Indonesia maupun Australia telah

White Paper on Australia's Foreign and Trade Policy. $7 \mathrm{Mei}$ 2002. 
mendasari praktik politik luar negeri masingmasing, berdasarkan asumsi-asumsi dan harapan-harapan semata. Kedua pemerintah mengabaikan realitas, yang sebenarnya merupakan faktor determinan, dalam proses pembuatan dan implementasi kebijakan luar negeri mereka. Dalam masalah Papua Merdeka kecenderungan itu semakin tampak.

Tercatat dalam sejarah sebenarnya sejak 1969, yaitu sejak dilaksanakannya "The Act of Free Choice" atau PEPERA (Pemungutan Kehendak Rakyat) untuk bertanya pada rakyat Papua apakah akan merdeka atau turut Republik Indonesia, pemerintah Australia selalu mendukung Indonesia hingga sekarang. Indonesia tampak selalu khawatir Australia akan mendukung Papua untuk merdeka. Kekhawatiran semakin tampak ketika Menteri Pertahanan, Ryamizard Ryacudu, dalam kunjungannya ke Sydney pada 21 Desember 2015 lalu harus mengeluarkan pernyataan: "Jangan ada negara yang mencoba untuk mendukung gerakan separatis di Papua (OPM)“.

Meskipun ternyata negara yang dimaksud ialah Vanuatu, negara kecil di Pasifik Selatan, tetapi pernyataan tersebut mengejutkan Menteri Luar Negeri Australa, Julie Bishop, dan Menteri Pertahanan Australia, Ann Pyne. Hal yang menjadi pertanyaan, apakah bisa pemerintah Indonesia selalu meminta pihak lain, khususnya Australia dan negaranegara kecil di Pasifik Selatan untuk tidak mencampuri masalah Papua, sementara secara geografis jarak mereka lebih dekat dibanding Jakarta, sebagai ibukota Indonesia. Bagaimana pemerintah akan menghadapi negara-negara Pasifik Selatan yang pembukaan kantor diplomatiknya masih dalam proses?

Apabila pemerintah Indonesia mengharap dukungan pemerintah Australia atas Papua sebagai bagian dari Indonesia yang tidak terpisahkan, sejak awal Indonesia sudah mendapatkannya. Hampir semua Perdana Menteri Australia mendukung Indonesia, baik Perdana Menteri yang bersahabat seperti Geogh Withlam dan Paul Keating pada masa Soeharto, maupun yang kurang bersahabat seperti John Howard dan Tony Abbot pada masa pemerintahan SBY. Akan tetapi , pemerintah Australia tidak mungkin melarang masyarakatnya untuk mendukung kemerdekaan Papua.

Kepedulian masyarakat Australia terhadap Papua sepertinya lebih banyak daripada kepedulian masyarakat Indonesia sendiri mengenai integritas Papua, sebagai bagian dari Republik. Hal ini terlihat dari banyaknya kelompok-kelompok aktivis Australia yang muncul seperti Free West Papua Campaign, Rise of the Morning Star-Melbourne, Freedom Flotilla for West Papua, AustraliaWest Papua Association. Belum lagi di Pasifik Selatan terdapat Fiji Solidarity Movement for West Papua's Freedom, dan lain lain. Mereka sangat aktif mengamati kebijakan pemerintah Indonesia di Papua, khususnya mengenai pelanggaran HAM, kekerasan, pelintas batas, dan keterbelakangan rakyat Papua.

Berdasarkan pengamatan perkembangan ini, pendekatan pemerintah Indonesia sebaiknya tidak hanya mengandalkan dukungan dari pemerintah Australia. Pemerintah sebaiknya mendorong masyarakat Indonesia agar memiliki kepedulian terhadap Papua, seperti halnya masyarakat Australia. Meskipun ada analisis yang mengatakan bahwa apapun kegiatan yang dilakukan masyarakat Australia untuk pendukung Papua merdeka, hal itu tidak akan memengaruhi dukungan pemerintah Australia terhadap pemerintah Indonesia. Tetap saja perlu diambil pelajaran dari peristiwa terlepasnya Timor Timur dari wilayah Indonesia, bahwa sikap pemerintah Australia bisa berubah. Australia yang semula mendukungan integrasi Timor Timur, berbalik menjadi mendukung kemerdekaan Timor Timur.

Selama ini orientasi politik luar negeri Australia tertuju pada Amerika Serikat. Pernyataan ini didasarkan pada keaktifan 
Angkatan Bersenjata Australia (Australian Defence Force) untuk bergabung dengan pasukan Amerika Serikat dalam operasi militer di Afghanistan sejak 2001, Irak pada tahun 2003, Suriah pada 2011, juga di saat perang Vietnam tahun 1960-an. Kepentingan Australia dalam operasi militer tersebut tidak begitu jelas, selain mendukung kepentingan Amerika. Sehingga dapat dianalogikan bahwa, dukungan Australia atas Papua juga akan tergantung pada dukungan Amerika Serikat kepada Indonesia.

Perkembangan terkhir bahwa pemerintah Indonesia akan meningkatkan hubungan dengan Australia dalam bidang politik, keamanan, ekonomi, dan kerja sama antarmasyarakat, seharusnya dijelaskan lebih konkret. Khususnya dalam membangun kerja sama antarmasyarakat, pemerintah Indonesia harus mempunyai kerangka kebijakan yang didasarkan pada aturan hukum yang jelas, sehingga dapat dijadikan pedoman masyarakat untuk bekerja sama dengan masyarakat Australia, yang umumnya lebih pro pada kemerdekaan Papua.

Bagi negara-negara yang berada di Pasifik Selatan, pemerintah telah menetapkan kebijakan dua pintu, artinya dukungan tidak hanya dicari dari Australia tetapi juga negara-negara Pasifik Selatan yang mempunyai kedekatan dengan Australia. Perlu diperhatikan bahwa negaranegara Pasifik Selatan terbagi dalam 3 wilayah utama yaitu Micronesia, Melanesia dan Polynesia. Sebaiknya Melanesia diberi prioritas karena kedekatan geografisnya. Negara-negara di wilayah ini, yaitu Vanuatu, Solomon, New Guinea, Bismarck Arch, Fiji, New Caledonesa dan Santa Cruz lebih aktif mendukung Gerakan Aceh Merdeka, dibandingkan wilayah lain. Untuk wilayah ini, dukungan dari pemerintah maupun masyarakat masih belum didapatkan sehingga perlu kebijakan yang menyeluruh dan diplomasi aktif dari Indonesia. Kembali mengambil pelajaran dari peristiwa Timor Timur, dukungan kepada Ramos Horta untuk memerdekakan Timor Timur justru datang dari negara-negara Afrika yang kurang dikenal secara internasional, seperti Ghana atau Guinea Bissau di Afrika Barat yang belum tersentuh diplomasi Indonesia.

Nampaknya prinsip "the right of self determination" atau hak untuk mengurusi diri sendiri dan prinsip "non intervention" atau tidak mencampuri negara lain, merupakan prinsip yang kaku jika terus dipegang dalam pergaulan internasional pada zaman yang sedang berubah. Di era globalisasi yang serba terbuka seperti saat ini, negara sangat sulit mengontrol intervensi ataupun infiltrasi dari luar kepada masyarakat. Pemerintah Australia dalam pertemuan di Sydney, menjamin kembali dukungan Papua sebagai bagian dari NKRI. Apakah Indonesia puas dengan jaminan ini?

Sebagai negara tetangga yang secara geografis berdekatan, Indonesia-Australia memiliki banyak sekali perbedaan yang dapat memicu perbedaan lain, termasuk politik luar negeri sehingga ada juga yang menggambarkan hubungan Indonesia-Australia sebagai dua orang yang tidur di tempat tidur yang sama, tetapi memimpikan hal yang berbeda. Perbedaan yang harus dipahami dari pihak Indonesia ialah, Australia tergabung dalam aliansi pertahanan dengan Amerika dan New Zealand yaitu Australia-New Zealand-US (ANZUS) yang mempunyai kesepakatan "common position", sehingga apapun yang diputuskan oleh ANZUS akan diikuti Australia. Oleh karena itu, selama Amerika mendukung Papua sebagai bagian dari NKRI, Australia juga akan melakukan hal serupa, pun sebaliknya.

Disamping itu, bagi Australia faktor domestik atau keadaan dalam negeri sangat memengaruhi kebijakan luar negerinya. Kemungkinan pemerintah Australia ingin menjalin hubungan baik dengan Indonesia, misalnya dalam kasus dukungan atas Papua sebagai bagian dari NKRI, jika rakyatnya tidak mendukung maka pemerintah Australia akan lebih mengikuti kehendak rakyatnya. 


\section{Memahami Kebijakan Luar Negeri Australia dalam Konteks Domestiknya}

Di Australia, aktor-aktor yang terlibat dalam kebijakan luar negeri menjadi semakin banyak dan beragam (Hudson, 1992). Banyak individu dan kelompok dalam masyarakat yang terlibat, baik memengaruhi proses pembuatan maupunimplementasinya. Bahkan, padabanyak kasus, masyarakat sipil seperti media, lembaga swadaya masyarakat, kelompok kepentingan atau kelompok penekan, dan organisasi sosial kemasyarakatan lainnya adalah yang paling banyak berperan dalam memengaruhi proses pembuatan dan implementasi kebijakan luar negeri Australia. Dengan demikian, seperti dikatakan oleh Gareth Evan:

"One cannot presume to define a role for Australian foreign policy ... without understanding the dynamics, and limitations, of the institutional processes which in practice have o be employed to develop and apply that policy. Who, then, does what, and how, in the making and implementation of Australian policy?"(Evan dan Grant, 1993:44).

Demi menemukan jawaban terhadap hal-hal yang spesifik dan rumit tersebut, pemerintah juga harus belajar dan memahami sistem politik dan pemerintahan Australia secara luas, peran media masanya, sistem kepartaian, karakter dan peran lembaga swadaya masyarakat, kelompok kepentingan atau kelompok penekan dalam sistem politik Australia, sistem dan fungsi parlemen, sifat dan karakter politisi tertentu, serta pola-pola interaksi di antara mereka. Sebagai contoh, kita harus mengetahui apa itu Green Party, siapa saja tokohnya, apa yang dilakukannya, seberapa kuat pengaruhnya, dan bagaimana pandangannya terhadap Indonesia. Hal yang sama juga harus dilakukan pada kelompok atau individu lainnya, terutama yang sikap dan tindakannya berpotensi menggangu hubungan Indonesia-Australia.
Pertimbangan Australia mendukung kemerdekaan Timor Timur misalnya, cenderung karena alasan ekonomi, yaitu untuk menyelamatkan wilayah sengketa perbatasan laut dengan Indonesia di Laut Timor, yang mengandung potensi kekayaan gas, mineral, dan minyak. Adapula alasan keamanan, karena Timor Timur yang bergejolak untuk menuntut kemerdekaan dari Indonesia akan memengaruhi stabilitas keamanan Australia. Kedekatan geofrafis akan memudahkan pelarian politik memasuki Australia. Bagi Australia, sikap politik luar negeri ini sudah memenuhi tuntutan kepentingan nasionalnya, terutama untuk menjaga perbatasan negara. Oleh karena itu, Australia terus mendukung perjuangan Timor Timur untuk merdeka tahun 2002 dan terlibat dalam referendum.

Belumjelas hubungan antara sikap Australia yang mendukung kemerdekaan Timor Timur dengan peristiwa Bom Bali 2002. Pada 12 Oktober 2002 terjadi pengeboman di Paddy's Club dan Sari Club di Jalan Legian Kuta Bali yang menewaskan kurang lebih 202 orang, 88 di antaranya orang Australia. Insiden ini dilanjutkan dengan bom di Kedutaan Australia di Jakarta pada September 2004 dan Bom Bali II pada bulan Oktober 2005, yang menewaskan 23 orang, 4 di antaranya warga Australia. Pelaku pengeboman, menurut laporan Kepolisian Republik Indonesia ialah jaringan Jamaah Islamiyah yang mempunyai hubungan dengan Al Qaeda. Peristiwa ini membuat kekhawatiran Australia tentang ancaman dari kelompok Islam militan Indonesia menjadi nyata. Dalam rangka melidungi warganya di dalam negeri, pemerintah Australia mengeluarkan peringatan perjalanan bagi warganya yang akan berkunjung ke Indonesia. Bagi Indonesia, meskipun peringatan tersebut tidak mengurangi jumlah wisatawan asal Australia yang datang ke Indonesia, namun pemerintah Australia dianggap telah menunjukkan sikap yang kurang bersahabat.

Bagi Indonesia, Australia cenderung provokatif, memancing ketidaksenangan 
terhadap Indonesia. Alasan keamanan dan kepentingan ekonomi Australia telah mengabaikan hubungan yang harmonis di antara kedua negara tetangga ini. Indonesia mulai bersikap tegas terhadap Australia atau warganya, seperti pada kasus Schapelle Leigh Corby. Warga negara Australia yang pada 8 Oktober 2004 ditangkap di Bandara Ngurai Rai, Denpasar karena kedapatan membawa 4,2 kg ganja. Corby dihukum 20 tahun penjara menurut keputusan Mahkamah Agung pada Januari 2006, karena ganja yang dibawa tergolong kelas I dan berbahaya. Beberapa usaha dilakukan pemerintah Australia untuk meringankan hukuman atau membebaskan Corby, tetapi tidak berhasil.

Masyarakat Indonesia dikejutkan pada 15 Mei 2005, ketika Corby mendapat remisi lima tahun hukuman, dan pada Februari 2014 Corby kembali memperoleh remisi dengan status bebas bersyarat. Muncul berbagai spekulasi bahwa pembebasan Corby merupakan hasil diplomasi khusus antara kedua negara. Corby "ditukar" dengan banyak awak buah kapal Indonesia yang ditahan Australia karena melanggar batas perairan internasional. Protes terhadap pembebasan Corby dicetuskan banyak pihak, termasuk oleh kelompok Front Pembela Islam (FPI). Ketua FPI, Munarman, menganggap pemerintah Indonesia tidak konsisten dalam memberantas narkoba, serta Australia adalah negara yang berpotensi menjadi negara asal para pengedar narkoba ke Indonesia, khususnya Bali. Kasus Corby merupakan salah satu bukti perbedaan persepsi menyangkut masalah keamanan. Di satu pihak, Australia menganggap Islam militan membahayakan keamanannaya, namun di pihak lain, Indonesia justru beranggapan Australia membahayakan keutuhan NKRI dan mendorong peredaran narkoba di Bali.

Kasus terakhir menyangkut narokba ialah dihukum matinya dua warga Australia, yaitu Myuran Sukumaran dan Andrew Chan. Dalam kasus yang dikenal dengan "Bali 9" ini, warga Australia melakukan protes besarbesaran atas keputusan pengadilan Indonesia dan mengecam pelaksanaan hukuman mati di Indonesia. Sikap warga Australia tersebut sangat bertentangan dengan desakan Australia pada Indonesia agar cepat menghukum mati pelaku Bom Bali I. Sikap Australia dilanjutkan dengan ancaman mengurangi beasiswa bagi pelajar Indonesia yang akan bersekolah di Australia.

Masalah lain yang menghambat hubungan Indonesia dan Australia menyangkut keamanan ialah masalah manusia perahu (boat people), yaitu pengungsi dari daerah-daerah konflik seperti Irak, Iran, Afghanistan, Vietnam, Sri Lanka dan Myanmar yang datang melalui perairan Indonesia menuju Australia untuk mencari suaka. Perdana Menteri Tony Abbot menolak kehadiran manusia perahu dan mengusir mereka keluar dari wilayah Australia demi menjaga perbatasan dan keamanan dalam negerinya. Indonesia sebagai negara tetangga yang memiliki perbatasan langsung dengan Australia terkena dampak harus menerima manusia perahu atas alasan kemanusiaan.

Sikap Australia tersebut memperumit hubungannya dengan Indonesia. Apalagi, ditemukan bukti adanya penyuapan oleh para pejabat Australia kepada awak perahu agar membawa kembali para manusia perahu ke Indonesia. Bukti ini ditemukan oleh pejabat Indonesia di Pulau Rote pada bulan Mei 2015, yang menahan kapal pembawa 65 manusia perahu asal Bangladesh, Sri Lanka, dan Myanmar yang akan berlayar ke Selandia Baru. ${ }^{5}$ Pemerintahan Abott tidak memberi jawaban yang memuaskan publik Indonesia. Kekhawatiran Australia akan ancaman keamanan perbatasannya dianggap telah melanggar prinsip-prinsip pembinaan diplomasi yang harmonis di antara negara bertetangga dan prinsip HAM yang telah menjadi universal, sejak PPB memerkenalkan

\footnotetext{
${ }^{5}$ International.sindonews.com/ Mei 2015
} 
Konvensi HAM Internasional pada 10 Desember 1948. Pada masa kepemimpinan Abbot, sebelum ia digantikan oleh Malcolm Turnbull pada September 2015, pengusiran manusia perahu masih dilanjutkan dengan pengiriman pesawat tanpa awak atau drone untuk mengawasi imigran yang datang dari Indonesia.

Hal utama yang mengikat Australia dengan Indonesia ialah kedekatan jarak, begitu juga keanggotaan di dalam Asia Pacific Economic Cooperation (APEC), G-20, dan PBB. Faktor-faktor ini nampaknya belum menjadi kekuatan yang menyatukan kedua Negara. Masih diperlukan faktor sentripetal lainnya agar hubungan Indonesia dan Australia dapat berjalan dengan lebih baik.

\section{Kesimpulan}

Dari penelitian ini dapat ditarik kesimpulan bahwa karakter security complex atau the pattern of amity and enmity antara Indonesia-Australia cukup kompleks. Kedua negara sama-sama mempunyai aspek amity dan enmity yang lainnya. The pattern of amity and enmity antara kedua negara ini relatif bersifat persisten, tidak terlalu banyak terpengaruh oleh perubahan lingkungan politik internal dan eksternal masing-masing. Secara umum aspek amity jauh lebih dominan dari pada aspek enmity. Walaupun demikian, setidaknya di permukaan atau di mata publik, hubungan kedua negara lebih diwarnai oleh ekspresi enmity daripada amity.

Beberapa pelajaran dapat diambil dari hubungan Indonesia-Australia selama ini. Pertama, Indonesia tidak bisa bertindak berdasarkan asumsi-asumsi dan harapanharapan bahwa pihak lain akan berbuat baik hanya karena kita percaya bahwa mereka seharusnya melakukan hal-hal seperti yang kita harapkan. Kedua, pencegahan jauh lebih baik dibanding mengatasi atau menyelesaikan hal-hal yang sudah terjadi. Seharusnya, sejak awal kita mencurahkan segenap sumber daya dan kemampuan diplomasi untuk mencegah Australia melakukan aspek enmity daripada amity. Dapat dipastikan, memaksa Australia membatalkan setiap kebijakan yang sudah diambil pasti jauh lebih sulit dibandingkan mencegah, misalnya dalam kasus visa untuk 42 WNI asal Papua. Ketiga, tidak ada cara lain, jika Indonesia ingin memetik keuntungan dari hubungan dengan Australia, maka segala aspek dari bangsa dan negara tersebut harus dipahami lebih dalam dan kritis, khususnya konfigurasi dan dinamika politik domestiknya.

\section{Daftar Pustaka}

Bell, Coral. (1998). Dependent Ally: A Study in Australian Foreign Policy. Sydney: Allen \& Unwin.

Burchill, Scott and Andrew Linklater (et.al). (1996). Theories of International Relations. London: Mac Millan Press.

Buzan, Barry, People. (1991). States and Fear: An Agenda for International Security Studies in the Post Cold War Era, $\left(2^{\text {nd }} E d\right)$. Boulder, Colorado: Lynne Rienner Publishers.

Biernacki, Richard. (2012). Reinventing Evidence in Social Inquiry: decoding Facts and Variables. New York: Palgrave Macmillan.

Departemen of Foreign Affairs and Trade Australia. Advancing the National Interest: Australia's White Paper on Foreign and Trade Policy. Canberra, 12 Februari 2003.

Desmond, Bail. (1991). Strange Neighbours: Australia-Indonesia Relationship. Unwin Hyman.

Evans, Gareth. (1993). Australia's Foreign Policy in the World of the 1990s. Melbourne: Melbourne University Press.

FA. Mediansky. (1992). Australia in a Changing World: New Foreign Policy Directions. Sydney: Maxwell MaxMillan Publishing.

Isaac, Ariail, Reed. (2011). Interpretation and Social Knowledge: On the Use of Theory in the Social Sciences. Chicago: University of Chicago Press. 
Jensen, Lloyd. (1982). Explaining Foreign Policy. Englewood Cliffs: Prentice Hall.

Klotz, Audie and Lynch, Cecelia. (2007). Strategies for Research in Constructivist International Relations. Armonk, NY: M E. Sharpe.

Leifer, Michael. (1983). Indonesia's Foreign Policy. Sydney: George Allen and Unwin.

Machie, Jamie. (2000). Australia and Indonesia Current Problems, Future Prospects.

Longueville, Double Way, New South Wales: Lowy Institute for International Policy.

King, Gary, Robert O. Keohane, and Sidney Verba. (1994). Designing Social Inquiry:

Scientific Inference in Qualitative Research. Princeton, NJ: Princeton University Press.

Keith, Punch. (2005). Introduction to Social Research, (2 ${ }^{\text {nd }} \cdot$ ed $)$. London: SAGE Publications.

Newman, Lawrence. (2003). Social Research Methods: Qualitative and Quantitative Approaches, $\left(5^{\text {th }}\right.$. ed $)$. New York: Allyn and Bacon.

Novotny, Daniel. (2010). Torn Between America and China: Elite Perceptions and Indonesian Foreign Policy. Singapore: Institute of Southesat Asian Studies.

Prasad, Pushkala. (2005). Crafting Qualitative Research: Working in The Post-Positivist Tradition. Armonk, NY: M. E. Sharpe.

Smith, Rodney. (1993). Politics in Australia. Sydney: Allen \& Unwin.
Smith, Steve, et al. (2008). Foreign Policy, Theories, Actors and Cases. Oxford: Oxford University Press.

Sprinz, Detlef F and Nahmias, (Eds.)/2007. Model, Numbers and Cases: Methods for Studying International Relations. Ann Arb Yael W. or, University of Michigan Press.

Weinstein, B. Franklin. (1976). Indonesian Foreign Policy and the Dilemma of

Dependence: from Soekarno to Suharto. Ithaca: Cornell University Press.

WJ. Hudson. The Australian People and Foreign Policy. Dalam FA. Mediansky. (Ed)/1992. Australia in a Changing World: New Foreign Policy Directions. Sydney: Maxwell Macmillan Publishing.

Yanow, Dvora and Schwartz-Shea, Peregrine. (Eds)/2006. Interpretation and

Method: Empirical Research Methods and The Interpretive Turn. Armonk, NY: M.E. Sharpe.

\section{Paper/Koran}

Hamilton,Natasha, dan McRae, Dave. 2015. Indonesia Balancing The United States and China, Aiming for Independnce. The United States Study Center at the University of Sydney, and Emerging US Security Partnership in South East Asia.

Kompas, 26 Oktober 2015 